\title{
$\underset{1}{\Rightarrow}$ DIAGNOSTIC PATHOLOGY
}

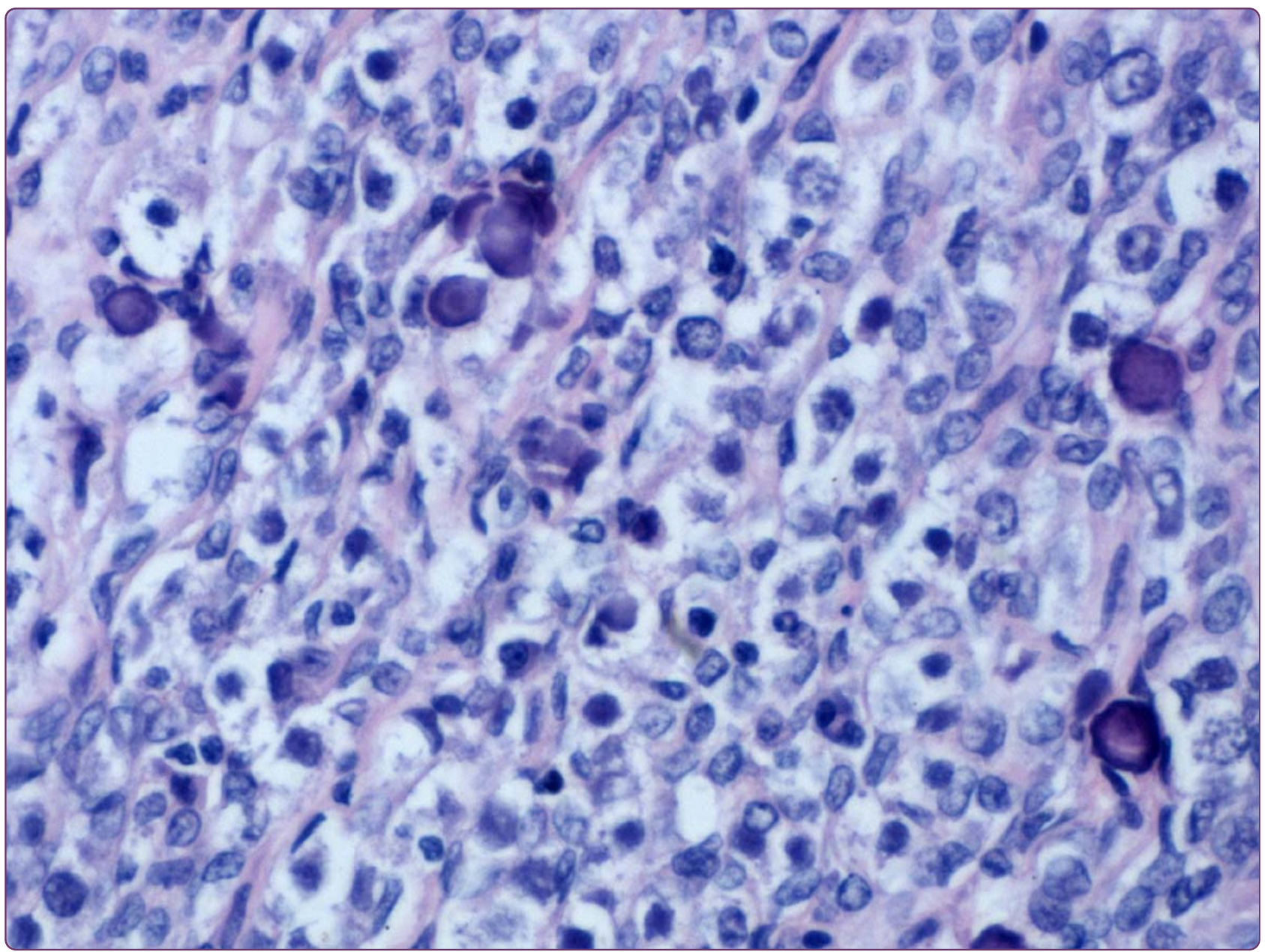

\section{Dysgerminoma in a case of 46, XY pure gonadal dysgenesis (swyer syndrome): a case report}

Han et al. 


\title{
Dysgerminoma in a case of $46, \mathrm{XY}$ pure gonadal dysgenesis (swyer syndrome): a case report
}

\author{
Yang Han, Yan Wang, Qingchang Li, Shundong Dai, Anguang He and Enhua Wang*
}

\begin{abstract}
Simple 46, XY gonadal dysgenesis syndrome, also called Swyer syndrome, is known as pure gonadal dysgenesis. Individuals with the syndrome are characterized by $46, X Y$ karyotype and phenotypically female with female genital appearance, normal Müllerian structures and absent testicular tissue. The condition usually first becomes apparent in adolescence with delayed puberty and primary amenorrhea due to the gonads have no hormonal or reproductive potential. Herein, we report a case of dysgerminoma diagnosed in a dysgenetic gonad of a 21-yearold patient with Swyer syndrome.
\end{abstract}

Keywords: dysgerminoma, Swyer syndrome, 46, XY pure gonadal dysgenesis

\section{Background}

Doctor Swyer described two women whom had a 46, XY karyotype, tall stature, primary amenorrhea, female external genitalia, normal vagina (albeit hypoestrogenised) and cervix in 1955 [1]. Individuals with Swyer syndrome are phenotypically female with unambiguously female genital appearance from birth and normal Müllerian structures. The patients usually first become apparent in adolescence with delayed puberty and primary amenorrhea due to the fact that the gonads have no hormonal or reproductive potential. Here, we report a case of dysgerminoma diagnosed in a dysgenetic gonad of a 21-year-old patient with Swyer syndrome.

\section{Clinical history}

A 21 years old patient with a history of primary amenorrhea, 46, XY karyotype, was admitted to the hospital complainging of a low abdominal mass. The patient is $164 \mathrm{~cm}$ tall. She has breast development (tanner IV). The pubic hair distribution is adult in type but decrease in total quantity. Her menstruation had not started until she took estradiol valerate and medroxyprogesterone for 15 months, which was prescribed by doctor in her 17 years old. In 19 years old, menstruation started, 6 days at intervals of 23-40 days, blood is ruby-red, sometimes blood clot. However, menstruation disappeared at the

\footnotetext{
* Correspondence: wangeh@yahoo.cn

Department of Pathology, College of Basic Medical Sciences and First

Affiliated Hospital of China Medical University, Shenyang, 110001 China
}

age of 20 because she stopped the pills. Chromosome analysis with fluorescence in situ hybridization revealed 46, XY. Color doppler imaging (CDI) showed the uterus was $3.22 \times 5.19 \times 2.80 \mathrm{~cm}$, thickness of the endometrium was $0.19 \mathrm{~cm}$ thick. There was a heterogenetic mixed echo $(5.50 \times 3.77 \mathrm{~cm})$ behind the cervix. Laboratory investigations showed CA125 was $11.53 \mathrm{U} / \mathrm{ml}$ (normal $0.00 \sim 35.00 \mathrm{U} / \mathrm{ml})$, testosterone free $(\mathrm{F}-\mathrm{TEST})$ was $34.5 \mathrm{pmol} / \mathrm{L}$ (normal $0.77 \sim 33.03 \mathrm{pmol} / \mathrm{L}$ ), FSH was $56.70 \mathrm{mIU} / \mathrm{ml}$, LH was $21.50 \mathrm{mIU} / \mathrm{ml}$, sex hormone binding globulin (SHBG) was $16.50 \mathrm{nmol} / \mathrm{L}$ (normal $18.0 \sim 114.0 \mathrm{nmol} / \mathrm{L}$ ) and carcino-embryonic antigen (CEA) was $0.55 \mathrm{ng} / \mathrm{ml}$ (normal $0 \sim 4.3 \mathrm{ng} / \mathrm{ml}$ ). Exploratory laparotomy was performed. Surgical findings: The uterus was small $(3.0 \times 5.0 \times 2.0 \mathrm{~cm})$. A $5.0 \times 5.0 \times$ $4.0 \mathrm{~cm}$ firm mass involved the right gonad with a smooth surface and good mobility. The left gonad was aplasia, like streak and without follicle. The bilateral fallopian tubes were slender. The serosa of the liver, the spleen and the stomach were smooth. There was no obvious nodule in the omentum. The result of the frozen section is malignant tumor of the ovary. Based on the agreement with the patient and her family bilateral salpingoopherectomy and hysterectomy $(\mathrm{BSOH})$ and lymph node dissection were performed. Due to tumor was classified as stageIA, adjuvant therapy was not commented. Written consent for publication was obtained from the patient. 


\section{Pathology \\ Gross}

A $5.0 \times 5.0 \times 4.0 \mathrm{~cm}$ firm mass involved the right gonad, while the left gonad appeared as streak gonad measuring $3.0 \times 0.6 \times 0.6 \mathrm{~cm}$. The tumor was encapsulated with a smooth surface. The cut surface of the tumor was solid, fleshy, lobulated and gray-yellow (Figure 1A). The bilateral fallopian tubes were slender. The uterus was small $(3.0 \times 5.0 \times 2.0 \mathrm{~cm})$ and the endometrium was smooth. The left gonad was $2.0 \times 0.6 \times 0.6 \mathrm{~cm}$ and appeared as streak gonad (Figure 1B).

\section{Histology and Immunohistochemistry}

The tumor and the other abscised tissues were fixed in $10 \%$ formalin and embedded in paraffin. Several 4- $\mu$ m sections were cut from each paraffin block, and one was stained with $\mathrm{HE}$ (hematoxylin and eosin), the others were stained with IHC (immunohistochemistry). Immunohistochemical staining was performed using the streptavidin-peroxidase system (Ultrasensitive; MaiXin Inc., Fuzhou, China) according to the manufacturer's instruction. Commercially available prediluted monoclonal antibodies against the following antigens were employed: CK(cell keratin), CD30, PLAP (placental alkaline phosphatase), CD117 (all Thermo Fisher Scientific Inc., Fremont, CA, USA).

\section{Results}

Microscopically, the tumor in the right dysgentic gonad showed the typical features of dysgerminoma. The tumor cells grouped themselves in well-defined nests separated by fibrous strands infiltrated by lymphocytes. The tumor cell membrane was prominent. The uniform, rounded tumor cells have clear to eosinophilic cytoplasm, and a central, large, rounded or flattened nucleus that contains one or a few prominent nucleoli. Calcification was seen (Figure $2 \mathrm{~A} \sim \mathrm{B}$ ). No metastases were detected. Immunohistochemically, the tumor cells were positive for PLAP, CD117, and CK, but negative for CD30. (Figure 2C E).
The squamous cells of the cervix was normal, and lymphocytes infiltrated was seen in the cervix tissue. (Figure 3A). The endometrium was in early proliferative phrase-thin surface epithelium; straight, short, narrow glands and compact stroma (Figure 3B). The left streak gonad had ovarian-type stroma (fibrous gonad), no primordial ovarian follicles and calcification was seen (Figure 3C). The fallopian tubes were slender and the tissue structure were normal (Figure 3D).

\section{Discussion}

The Swyer syndrome, 46, XY gonadal dysgenesis, belongs to the category of sexual abnormality [2]. The syndrome was complete/pure gonadal dysgenesis. The patients with 46, XY gonadal dysgenesis are diagnosed in early adolescence with delayed pubertal development. The patients' mesonephric ducts (Wolffian ducts) are in atrophy, paramesonephric ducts (Müllerian ducts) develops to uterus, fallopian tubes and part of the vagina as a result of lacking testosterone and inhibitor of Müllerian ducts. As expected they show elevated gonadotropins, normal female levels of androgens, low levels of estrogens, female external genitalia, uterus and fallopian tubes. Minimal breast enlargement reflects peripheral aromatization of androgens. Both gonads display fibrous tissue that vaguely resembles ovarian stroma but no follicles. The etiology of 46, XY pure gonad dysgenesis is thought to be a shot arm Y chromosome deletion involving SRY (putative testicular-determining factor gene), a mutation in other genes that leads to inhibition of SRY function or mutation of SRY function [3].

Swyer syndrome should be differentiated from the following two female phenotype (karyotype XY) syndrome. One is the familial syndrome of testicular feminization, the most common type of male pseudohermaphroditism. It occurs in individuals with a normal male chromosome constitution with an end-organ defect (androgen insensibility). It characterized by the presence

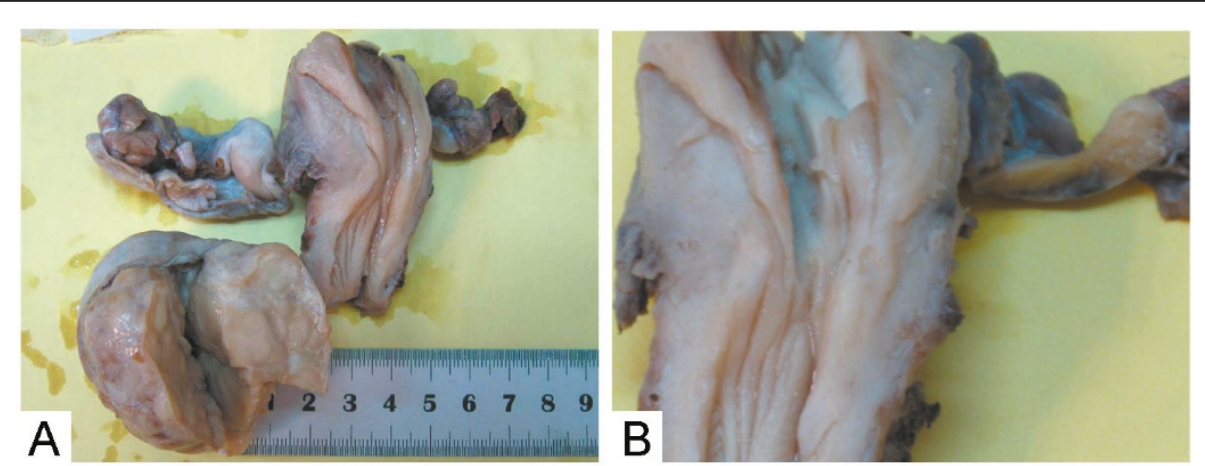

Figure 1 The right gonad was a $5.0 \times 5.0 \times 4.0 \mathrm{~cm}$ firm mass, encapsulated, with gritty gray-yellow cut surface. The cut surface of the tumor was solid, fleshy, lobulated and gray (A). The double fallopian tubes were slender. The uterus was small $(3.0 \times 5.0 \times 2.0 \mathrm{~cm})$ and the endometrium was smooth. The left gonad was $2.0 \times 0.6 \times 0.6 \mathrm{~cm}$ and appeared as streak gonad (B). 


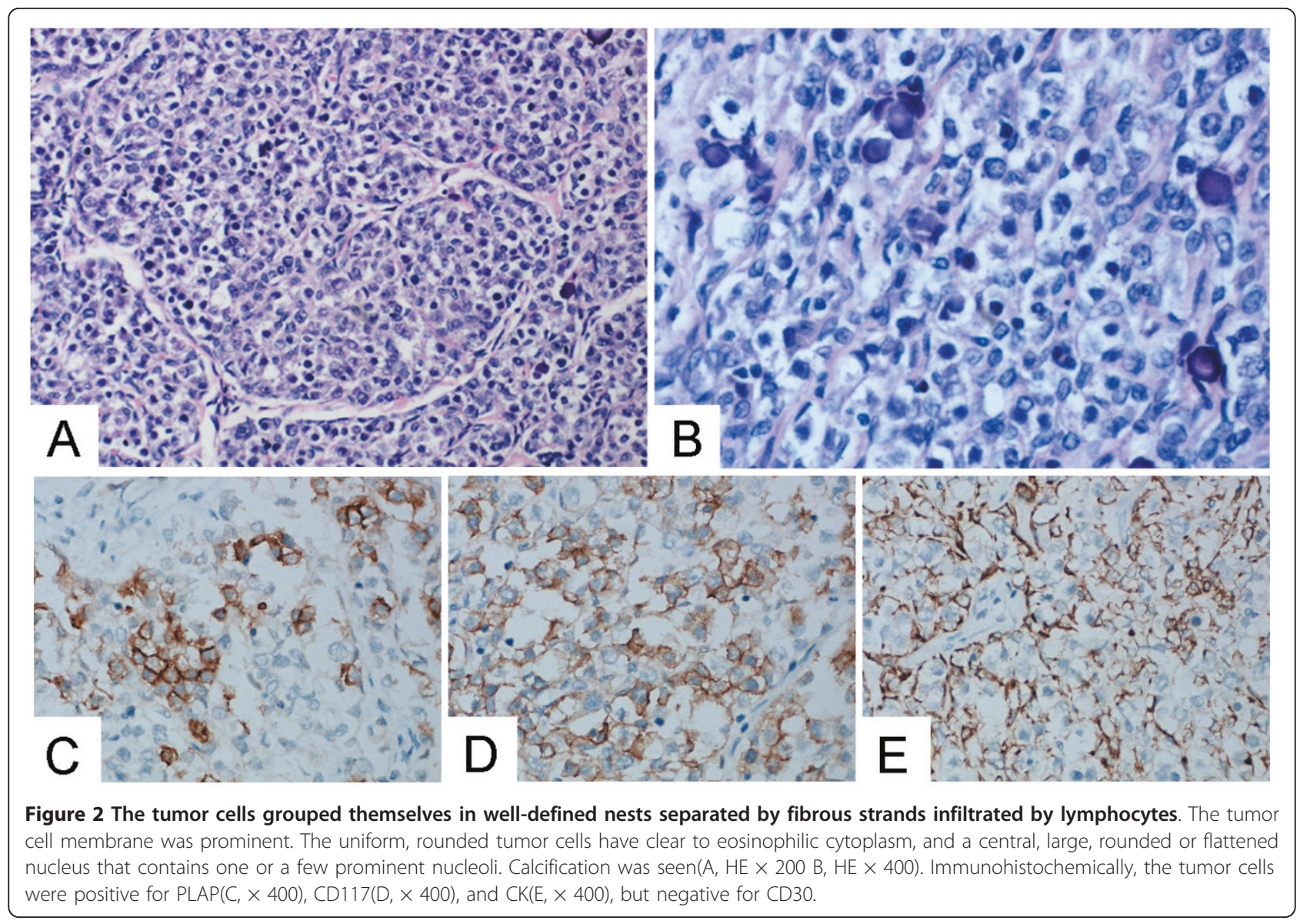

of several well-developed female secondary sex characteristics. Individuals are found to have a vagina (not a true vagina, but like a small "cupule"), bilateral cryptorchid testes but no uterus $[4,5]$. The other is true hermaphrodites, which may have ovotestes containing both ova and immature seminiferous tubules or other combinations of ovary and testis [6,7].

In patients with gonadal dysgenesis, either "pure"(with a $46, \mathrm{XX}$ or $46, \mathrm{XY}$ karyotype) or associated with the somatic features of Turner's syndrome (with a 45,XO karyotype), both gonads are represented by a streak of fibrous tissue that vaguely resembles ovarian stroma $[8,9]$. Previously thought these patients do not seem to have an increased incidence of gonadal tumors [10]. But modern studies show patients with $46, \mathrm{XY}$ pure gonadal dysgenesis are at a higher risk of developing gonadoblastoma and dysgerminoma, and may occur even in young ages. The incidence of Swyer syndrome is 1:100 $000[11,12]$. A bilateral gonadectomy should be done especially by laparoscopy when a Swyer syndrome is discovered in order to avoid the risk of malignant transformation. There is possibility of pregnancy by oocyte donation in some countries if the uterus was not removed for a malignant etiology.
In this report, we provide a case of dysgerminoma diagnosed in a dysgenetic gonad of a 21-year-old patient with Swyer syndrome, who presented with primary amenorrhea and infertility of five years duration. Karyotype was consistent with $46, \mathrm{XY}$ (pure). In our case, testosterone free was $34.5 \mathrm{pmol} / \mathrm{L}$, sex hormone binding globulin was $16.50 \mathrm{nmol} / \mathrm{L}$, and menstrual function was associated with estradiol valerate and medroxyprogesterone prescribed by doctor. Estrogen and progestin sequential therapy supports female secondary sex development in patients with gonadal dysgenesis. The patient did not have a bilateral gonadectomy after knowing she has a 46, XY caryotype because she wanted to be pregnant and did not believe she had the risk of suffering from malignent of ovary. It is necessary to take the familial screening of Swyer syndrome cases. As a malignant germ cell tumor of the ovary, dysgerminoma can be found either in a pure form or mixed with other germinal elements. Therefore in premenarchal patients with a pelvic mass, the karyotype should be determined.

Differential diagnosis for dysgerminoma include diffuse large B cell lymphoma, poorly differentiated carcinoma, embryonal carcinoma and gonadoblastoma. 


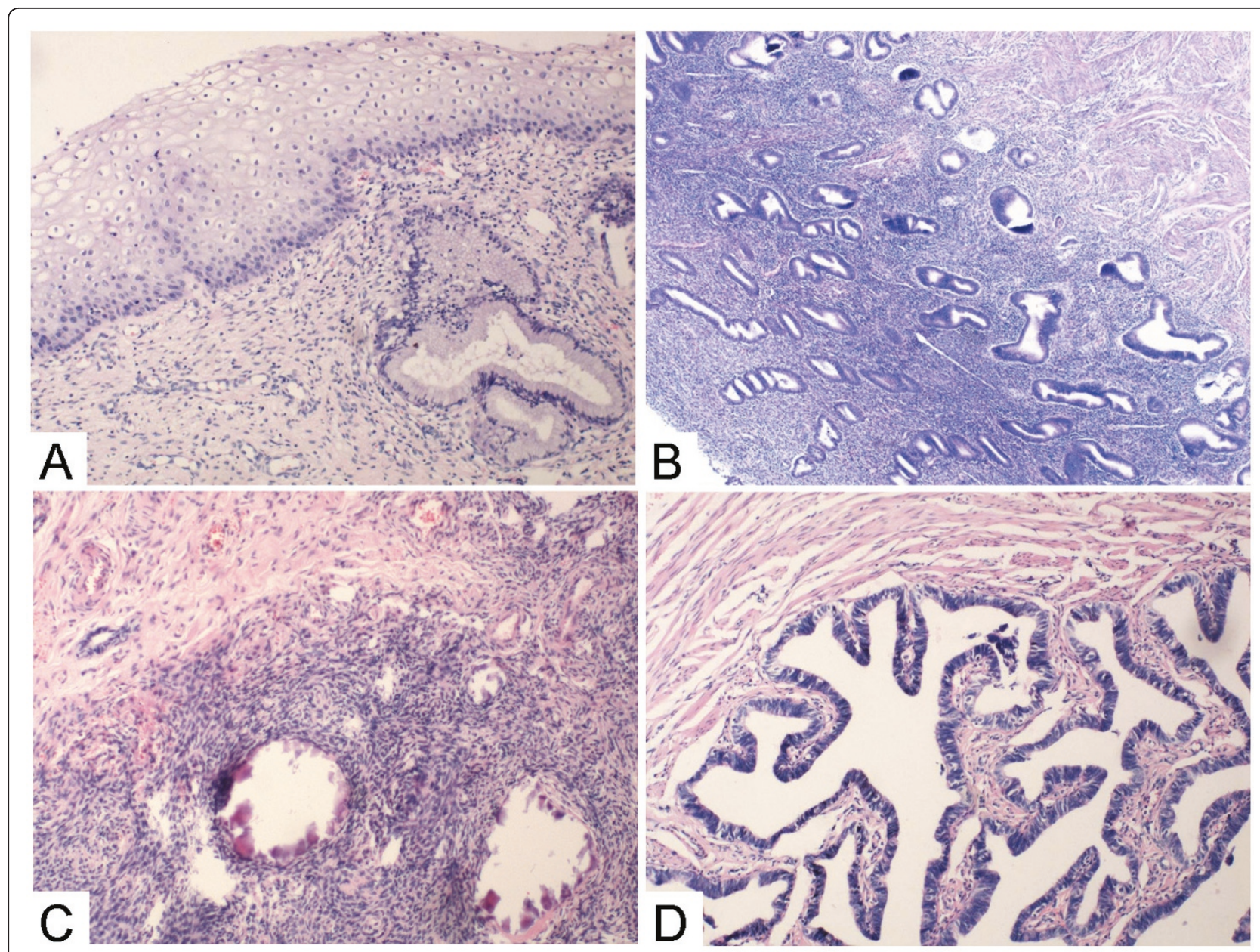

Figure 3 The squamous cells of the cervix was normal, and lymphocytes infiltrated was seen in the cervix tissue (A HE $\times 100)$. The endometrium was in early proliferative phrase (B HE $\times 40$ ). The left streak gonad with ovarian-type stroma, no primordial ovarian follicles and calcification was seen $(C H E \times 100)$. The tissue structure of the fallopian tubes were normal $(\mathrm{D} \mathrm{HE} \times 200)$.

Coexistence of dysgerminoma and gonadoblastoma is seen in about $50 \%$ of cases [13]. Histologic appearance of gonadoblastoma may be altered by hyalinization, calcification, and/or overgrowth of a malignant germ cell element predominantly dysgerminoma. Maleki et al. reported a case of dysgerminoma and gonadoblastoma in a dysgenetic gonad on a touch preparation that described cytomorphologic findings of both neoplasms [14].

About $65 \%$ of dysgerminomas are stage I at diagnosis. About $85 \sim 90 \%$ of stage I tumors are confined to one ovary; $10 \sim 15 \%$ are bilateral. Dysgerminoma is the only germ cell malignancy that has this significant rate of bilaterality, other germ cell tumors being rarely bilateral. The treatment of patient with early disgerminoma is resection of the primary lesion and proper surgical staging. Chemotherapy and/or radiotherapy are administered to patients with metastases. In patients whose contralateral ovary has been preserved, some disease can develop in $5 \sim 10 \%$ of the retained gonads over the next 2 years [15].

\section{Acknowledgements}

We wish to thank the colleagues in the Laboratory of Hematology of the First Affiliated Hospital of China Medical University. Special thanks to Dr. Wang Yazhu and Dr. Liang ying for the chromosomal analysis.

\section{Authors' contributions}

$\mathrm{YH}$ analyzed the data and wrote the manuscript as a major contributor. YW, $\mathrm{QL}$ and SD contributed to management of the patient. AH and EW carried out the histopathological evaluation and helped to write manuscript. All authors have read and approved the final manuscript.

\section{Competing interests}

The authors declare that they have no competing interests.

Received: 23 June 2011 Accepted: 19 September 2011

Published: 19 September 2011

\section{References}

1. Swyer Gl: Male pseudohermaphroditism: a hitherto undescribed form. $\mathrm{Br}$ Med J 1955, 2(4941):709-712. 
2. Guidozzi F, Ball J, Spurdle A: 46, XY pure gonadal dysgenesis (SwyerJames syndrome)-Y or Y not?: a review. Obstet Gynecol Surv 1994, 49(2):138-146.

3. Behzadian MA, Tho SP, McDonough PG: The presence of the testicular determining sequence, $\mathrm{SRY}$, in $46, \mathrm{XY}$ females with gonadal dysgenesis (Swyer syndrome). Am J Obstet Gynecol 1991, 165(6 Pt 1):1887-1890.

4. Michalkiewicz W, Baron J, Przybora L: Incomplete Testicular Feminization Syndrome. (Clinical, Hormonal, and Histological Study of 3 Familial Cases). Endokrynologia Polska 1965, 16:205-216.

5. Bisceglia M, Magro G, Ben Dor D: Familial complete androgen insensitivity syndrome (Morris syndrome or testicular feminization syndrome) in 2 sisters. Adv Anat Pathol 2008, 15(2):113-117.

6. Jones HW Jr, Ferguson-Smith MA, Heller RH: Pathologic and Cytogenetic Findings in True Hermaphroditism; Report of 6 Cases and Review of 23 Cases from the Literature. Obstet Gynecol 1965, 25:435-447.

7. Kim KR, Kwon Y, Joung JY, Kim KS, Ayala AG, Ro JY: True hermaphroditism and mixed gonadal dysgenesis in young children: a clinicopathologic study of 10 cases. Mod Pathol 2002, 15(10):1013-1019.

8. Sohval AR: The Syndrome of Pure Gonadal Dysgenesis. Am J Med 1965, 38:615-625.

9. Jones HW Jr, Ferguson-Smith MA, Heller RH: The Pathology and Cytogenetics of Gonadal Agenesis. Am J Obstet Gynecol 1963, 87:578-600

10. Taylor H, Barter RH, Jacobson CB: Neoplasms of dysgenetic gonads. Am J Obstet Gynecol 1966, 96(6):816-823.

11. Coutin AS, Hamy A, Fondevilla M, Savigny B, Paineau J, Visset J: Pure 46XY gonadal dysgenesis. J Gynecol Obstet Biol Reprod (Paris) 1996, 25(8):792-796

12. Behtash N, Karimi Zarchi M: Dysgerminoma in three patients with Swyer syndrome. World I Surg Oncol 2007, 5:71.

13. Ben Temime R, Chachial A, Attial L, Ghodbanel I, Makhloufl T, Koubaal A, Kourda N, Ben Jilani S, Dammak T, El May A, et al: 46 XY pure gonadal dysgenesis with gonadoblastoma and dysgerminoma. La Tunisie medicale 2008, 86(7):710-713.

14. Maleki Z, Loveless M, Fraig M: Coexistence of gonadoblastoma and dysgerminoma in a dysgenetic gonad on touch preparation: a case report. Diagn Cytopathol 2010, 39(1):42-44.

15. Casey AC, Bhodauria S, Shapter A, Nieberg R, Berek JS, Farias-Eisner R: Dysgerminoma: the role of conservative surgery. Gynecol Oncol 1996, 63(3):352-357.

doi:10.1186/1746-1596-6-84

Cite this article as: Han et al:: Dysgerminoma in a case of $46, \mathrm{XY}$ pure gonadal dysgenesis (swyer syndrome): a case report. Diagnostic

Pathology 2011 6:84.

\section{Submit your next manuscript to BioMed Central and take full advantage of:}

- Convenient online submission

- Thorough peer review

- No space constraints or color figure charges

- Immediate publication on acceptance

- Inclusion in PubMed, CAS, Scopus and Google Scholar

- Research which is freely available for redistribution 